\title{
Influences of Product Involvement and Symbolic Consumption Cues in Advertisements on Consumer Attitudes
}

\author{
Chao-Ming Yang ${ }^{1}$ \\ ${ }^{1}$ Department of Visual Communication Design, Ming Chi University of Technology, New Taipei City, Taiwan \\ Correspondence: Chao-Ming Yang, 84 Gungjuan Rd., Taishan Dist., New Taipei City 24301, Taiwan. E-mail: \\ yangcm@mail.mcut.edu.tw
}

Received: February 19, 2019

Accepted: May 5, 2019 Online Published: May 21, 2019

doi:10.5539/ijms.v11n2p15

URL: https://doi.org/10.5539/ijms.v11n2p15

\begin{abstract}
Symbolic consumption has become pervasive in daily life; advertisements focusing on brand awareness and celebrity endorsements involve strong product symbols and serve as a persuasive advertising tool. This study employed a $2 \times 2$ between-subject experimental design to investigate the influence of two independent variables, namely the level of consumer product involvement (high and low levels of involvement) and types of symbolic cues (brand and celebrity symbols), on consumer attitudes toward advertisements $\left(\mathrm{A}_{\mathrm{ad}}\right)$ and brands $\left(\mathrm{A}_{\mathrm{b}}\right)$. Four notable findings were revealed: (1) the level of participant product involvement affected their fondness for $A_{a d}$ and $A_{b}$; (2) symbolic cues affected participant $A_{a d}$ and $A_{b}$; (3) participants with a high level of product involvement exhibited more positive $\mathrm{A}_{\mathrm{ad}}$; and (4) participants with low product involvement demonstrated more positive $A_{b}$. In the contemporary advertising market, how enterprises can enable a product to convey a certain symbolic meaning has become particularly critical, and enterprises should not ignore the influences that symbolic consumption may have on consumers. These study results serve as a reference for enterprises and advising agents for devising future product advertising strategies.
\end{abstract}

Keywords: symbolic consumption, product involvement, brand awareness, celebrity endorsement

\section{Introduction}

An increase in the number of symbolic elements in commercial advertisements has been observed in the last few years. Moreover, consumer needs have gone beyond those related to the functional features of a product to incorporate their symbolic meanings (Stratton \& Northcote, 2016). Consumption based on such needs is referred to as symbolic consumption (Luna-Cortés, 2016; Ekinci, Sirakaya-Turk, \& Preciado, 2011). Scholars have considered symbolic consumption as a contemporary consumption phenomenon derived from the interaction between private and sociocultural worlds. The private world refers to inward-facing satisfaction and the sociocultural world denotes outward-facing identity (Elliott \& Perry, 2007; Holt, 1995; Richins, 1994). Currently, the emphasis on brand awareness and celebrity endorsements in product advertisements indicates the importance of symbolic consumption (Kim, Lee, \& Prideaux, 2014; Amos, Holmes, \& Strutton, 2008). The two aforementioned advertising elements are effective persuasion tactics in advertising.

Supanvanij and Amine (2000) suggested that brands serve as crucial cues for consumers to distinguish between product types and quality when making purchases. A brand plays a role in product identification and represents the effectiveness of symbolization (Faircloth, Capella, \& Alford, 2000). Advertisements strengthened by brand effects subconsciously affect consumer attitudes and behaviors (Jansen, Sobel, \& Zhang, 2011). Celebrity endorsements are advertising tactics that involve companies inviting influential public figures, such as experts, entertainers, and politicians, to endorse their products; it is a widely used advertising tactic aimed at creating "celebrity effects" (Sridevi, 2014). This type of advertisement involves strong symbolism. These symbols elicit higher advertisement involvement in consumers (Brown \& Marika, 2016) and unconsciously increase their fondness for advertised products through their admiration for the affiliated celebrities (Amos, Holmes, \& Strutton, 2008).

In summary, brand names and celebrity endorsements shown in advertisements are both of symbolic importance for contemporary consumers. Specifically, brand names can represent a consumer's social status, and celebrity endorsements reflect a consumer's adherence to popular culture. However, studies have predominantly discussed the two symbolic advertising concepts separately (Szymanowski \& Gijsbrechts, 2012; Schembri, Merrilees, \& 
Kristiansen, 2010; Amos, Holmes, \& Strutton, 2008; Park \& Yang, 2010); few studies have analyzed the two concepts under a single research framework. This was a gap this study aimed to fill. Understanding symbolic advertising messages involves people using their cognitive elaboration ability (DeRosia, 2008; Phillips, 2000), indicating that individual differences are an essential moderator variable in message processing (Machiels \& Karnal, 2015). Accordingly, this study, from the perspective of product involvement, discussed brand and celebrity symbols under a single research framework to explore the phenomenon of symbolic consumption resulting from advertisements and compared the effectiveness of the two advertisement types.

\section{Theoretical Background}

\subsection{Symbolic Consumption Theory}

Lee (2013) defined symbolic consumption as individuals purchasing particular products and using the meanings behind these products to convey a certain image of themselves. From the perspective of contemporary marketing strategies, symbolic consumption not only pertains to products and brands (Clammer, 1992; Csikszentmihalyi \& Rochberg-Halton, 1981; Dittmar, 1992; Fenollar \& Ruíz, 2006; Ger \& Belk, 1996; Lorenzi, 1991; McCracken, 1987) but is also closely related to the active self-creation of consumers (Ekinci et al., 2013; Luna-Cortés, 2016). The phenomenon of symbolic consumption in today's society has become more salient due to the influences of capitalism and mass media; when making consumption decisions, people have started to consider factors beyond the functional features of products and have begun to emphasize the symbolic meanings, namely the sociocultural value of products (Baudrillard, 2005). Symbolic consumption involves a connection between individual consumers and their sociocultural surroundings and the establishment of self-concepts. Different symbols elicit different consumer attitudes toward the advertised information (Ahuvia et al., 2005; Bhat \& Reddy, 1998; Dittmar, 2008). Accordingly, this study proposed the following hypotheses:

(1) H1a: In an advertisement containing symbolic consumption, the types of symbolic cues used affect consumer attitudes toward the advertisement.

(2) H1b: In an advertisement containing symbolic consumption, the types of symbolic cues used affect consumer attitudes toward the brand.

Baudrillard (1968) considered all consumer products to be symbolic objects; he suggested that consumption is an activity pertaining to a system of symbols and that people buy particular products not only for their functional uses but also because of the symbolic meanings carried by the products. Products are given symbolic meanings by the media, and people are influenced by such meanings in their consumption of products (Baudrillard, 1970). After people's basic material needs have been fulfilled, they use their remaining resources to engage in conspicuous consumption (O'Cass \& McEwen, 2004), which refers to consumers' use of product symbolism to demonstrate their perceived wealth. Conspicuous consumption is thus considered an extreme type of symbolic consumption (Charles, Hurst, \& Roussanov, 2009). Moreover, in symbolic consumption, consumers connect their objectives with their products constantly through product involvement, which denotes the extent to which a consumer engages in a product as well the consumer's subjective meanings and perceived values of the product (Zaichkowsky, 1985). Therefore, consumer identity should not be ignored in the discussion of symbolic consumption; specifically, consumers with different characteristics exhibit different consumption behaviors and different acceptance levels of various types of advertising (Luna-Cortés, 2016). Accordingly, the following hypotheses were proposed:

(3) H2a: In an advertisement containing symbolic consumption, the level of product involvement affects consumer attitudes toward the advertisement.

(4) H2b: In an advertisement containing symbolic consumption, the level of product involvement affects consumer attitudes toward the brand.

\subsection{Brand Awareness Effects}

Supanvanij and Amine (2000) suggested that brand names are valuable consumption symbols because they increase not only product revenue but also people's loyalty to products, and these effects of brand names on products are referred to as brand awareness effects. Brand awareness effects are prevalent in contemporary consumer culture. In addition to functionalities and prices, many consumers pay special attention to the consumption values of products, which enhance their self-identity, increase their social status, and indulge their vanity (Jansen, Sobel, \& Zhang, 2011). From the perspective of consumer culture theory, brands represent the consumers' limited ability to infer product quality prior to actual purchases and symbolize the trustworthiness of the products (Supanvanij \& Amine, 2000). Dodds, Monroe, and Grewal (1991) suggested that brand names are crucial determinants of consumers' perception of product quality and that consumer fondness for brands 
essentially affect their judgment of product quality and values as well as subsequent purchase intentions.

Furthermore, Shimp (1993) considered that a good brand name elicits affective responses in a consumer, such as feelings of trust, confidence, security, status, and durability. Studies have shown that the brand effects were associated with vendors and the reliability of their websites and products, and such effects influenced the perceived trustworthiness of advertisers by consumers (Schultz, 2008; Jansen et al., 2011). Kay (2006) argued that an advertisement displaying salient brand personality easily evoked positive emotions toward the advertised product. Moreover, strong brands give consumers the power to differentiate between products during purchases and make decisions accordingly. Petruzzellis (2007) discovered that Italian mobile phone consumers placed more emphasis on brands than on other product factors such as external design, aesthetics, and interface. In summary, the statements and findings of the aforementioned studies can be explained by consumer self-consistency and self-esteem (Sirgy, 1982; Fournier, 1998). Specifically, consumers have positive responses to advertising information of brands that concurrently satisfy their consumption desires and increase their self-image. Accordingly, the present study proposed the following hypotheses:

(5) H3a: An advertisement containing more brand-oriented symbolic cues evokes more positive attitudes toward the advertisement in consumers with high product involvement.

(6) H3b: An advertisement containing more brand-oriented symbolic cues evokes more positive attitudes toward the brand in consumers with high product involvement.

\subsection{Celebrity Endorsement Effect}

Celebrity endorsement is a prevalent (Biswas, Biswas, \& Das 2006) marketing characteristic of contemporary consumer markets (McCracken, 1989). Various scholars and businesses believe that celebrity endorsement can effectively create positive consumer attitudes toward products because consumers' fondness for the affiliated celebrities may be transferred to the advertised products (Kaikati, 1987; Ohanian, 1991; Tripp et al., 1994; Goldsmith et al., 2000; Erdogan et al., 2001); such persuasive advertising effects are termed celebrity endorsement effects (Eisend \& Langner, 2010). Park and Yang (2010) posited that celebrities or entertainers are considered to be sociocultural symbols that signify multiple consumption-related implications, namely admiration, fondness, following, and conspicuousness. Furthermore, consumers engaging in constant consumption to live like celebrities they are fond of a phenomenon resulting from rapid technological and media-related developments in contemporary society.

Generally, celebrity endorsements are costly, and such costs are usually passed on to consumers. However, consumers place a considerable amount of emphasis on the role of product endorsers in purchasing decisions, whether these products carry unique meanings in consumption markets, and whether the product price is set higher than average. Atkin and Block (1983) provided insights that might explain the aforementioned phenomenon. According to these scholars, celebrity effects are underpinned by a consumer's tendency to trust endorsers and have faith that these celebrities genuinely adore and use the products. Consequently, consumers (i.e., celebrity followers) project their fondness for these celebrities onto the endorsed products. A study also showed that tactics related to persuasion, namely using celebrity endorsement to increase advertising effects, are more effective when consumers have low product involvement (Petty, Cacioppo, \& Schumann, 1983). Celebrity endorsements elicit more positive attitudes in consumers with low product involvement (Sridevi, 2014), and sending advertising messages through celebrities increases advertising appeal, product attention, message recall, and product favoritism in such consumers (Kamins, 1989; Pelsmacker et al., 2004; Priester \& Petty, 2003). Accordingly, the following hypotheses were proposed:

(7) H4a: An advertisement containing more celebrity-oriented symbolic cues evokes more positive attitudes toward the advertisement in consumers with low product involvement.

(8) H4b: An advertisement containing more celebrity-oriented symbolic cues evokes more positive attitudes toward the brand in consumers with low product involvement.

\section{Research Methods}

\subsection{Experimental Variables}

The present study incorporated product involvement as the first independent variable in accordance with the study of Belanchea, Flavián, and Pérez-Rueda (2017) and modified the product involvement scale developed by Wang, Yu, and Wei (2012). Specifically, we divided participants into high product involvement and low product involvement (hereafter referred to as high-involvement and low-involvement, respectively) groups, namely those who pay more and less attention (respectively) to product information and are more active and inactive (respectively) in acquiring product information. 
Symbolic cues were incorporated as the second independent variable. In accordance with the studies of Supanvanij and Amine (2000) and Eisend and Langner (2010), we classified symbolic cues as brand-oriented symbolic cues, which refer to brand name-based messages used in advertisements to increase advertising persuasiveness, and celebrity-oriented symbolic cues, namely celebrity-based messages used in advertisements to increase advertising persuasiveness.

Finally, studies have shown that consumers are persuaded by an advertisement only when they are stimulated by the advertising messages to change their attitudes; the persuasive advertising effect is thus achieved (Petty, Fabrigar, \& Wegener, 2003; Yoon, 2015). Therefore, changes in customer attitudes after they have received advertising messages can be used to investigate the persuasiveness of the advertisement text (Ang \& Lim, 2006; Martin et al., 2003). Accordingly, the present study adopted two dependent variables, namely consumer attitudes toward advertisements $\left(\mathrm{A}_{\mathrm{ad}}\right)$ and consumer attitudes toward brands $\left(\mathrm{A}_{\mathrm{b}}\right)$, which refer to a consumer's overall response to an advertisement and their overall impression of an advertised brand after they have received advertising messages, respectively (Sallam, 2011).

\subsection{Administration of the Pretest Questionnaire}

A 7-point Likert scale, (ranging from strongly disagree $=1$ to strongly agree $=7$ ) was employed. Before the full-scale experiment was conducted, we invited 30 college students to participate in a pretest, in which we provided the participants with mobile advertisements of iPhones. The collected data were used to conduct the Cronbach's $\alpha$ test, and the internal consistency reliability of the questionnaire was revealed $(\alpha=.85-.89>.7)$, demonstrating a high level of reliability. The following section elaborates on the questionnaire items:

(1) Product involvement: I am accustomed to using this product; I am interested in the product information; this product carries a significant meaning to me; this product meets my needs; and I am willing to spend time acquiring information related to the product. This dimension exhibited an internal consistency reliability value $(\alpha)$ of .89 .

(2) Attitudes toward advertisements $\left(\mathrm{A}_{\mathrm{ad}}\right)$ : This advertisement is appealing to me; I think this advertisement is impressive; I think this advertisement is interesting; I think this advertisement is not of value; and overall, I like the advertisement design. This dimension had an internal consistency reliability value $(\alpha)$ of .87 .

(3) Attitudes toward brands $\left(\mathrm{A}_{\mathrm{b}}\right)$ : The advertised brand looks good to me; I think the advertised brand can reflect my personal taste; the advertised brand has a special meaning to me; after viewing this advertisement, I developed a good impression of the advertised brand; and the advertised brand seems trustworthy and reliable. This dimension demonstrated an internal consistency reliability value $(\alpha)$ of .85 .

\subsection{Experimental Design and Stimuli}

This study adopted a $2 \times 2$ between-subject experimental design, with the two independent variables being product involvement (high and low) and symbolic cues (brand-oriented and celebrity-oriented). This study used advertisements of sports footwear as the experimental stimuli; this product was chosen because sports footwear is one of the most popular products among youths and exhibits high consumer conformity regarding brands and celebrity endorsements are common.

To identify brands and endorsers that can most accurately reflect consumer behaviors in this study, we selected the top five brands from a ranking of the world's top 10 most popular sports footwear brands (i.e., Nike, Adidas, Reebok, Puma, and Air Jordan) and the five most renowned sports brand endorsers among Taiwanese consumers (i.e., Michael Jordan, Kobe Bryant, Stephen Curry, LeBron James, and James Harden) as the experimental stimuli in the pilot experiment. The result indicated that Nike and Adidas exhibited the highest brand awareness, and NBA players LeBron James and Stephen Curry were the most popular endorsers among all. Subsequently, the two brands and endorsers were used in the production of experimental stimuli, and four experimental conditions were designed (Figures. 1-4). 


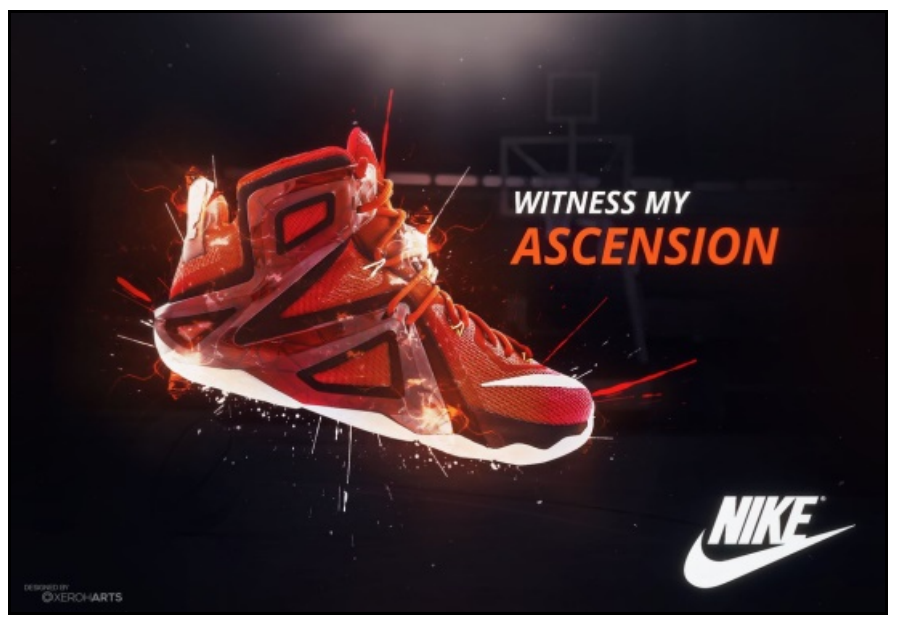

Figure 1. Experimental condition A-Brand-oriented symbolic cue

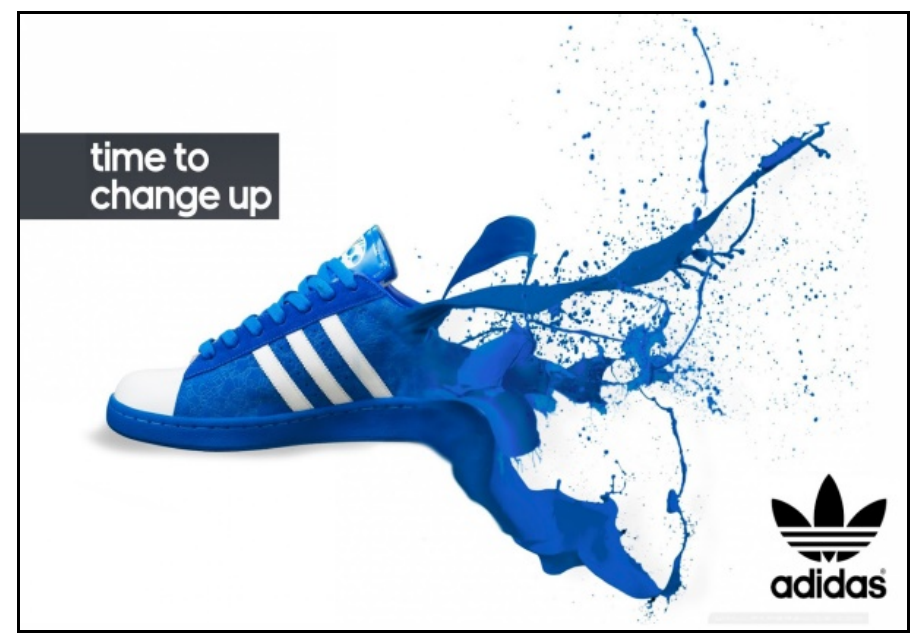

Figure 2. Experimental condition B-Brand-oriented symbolic cue

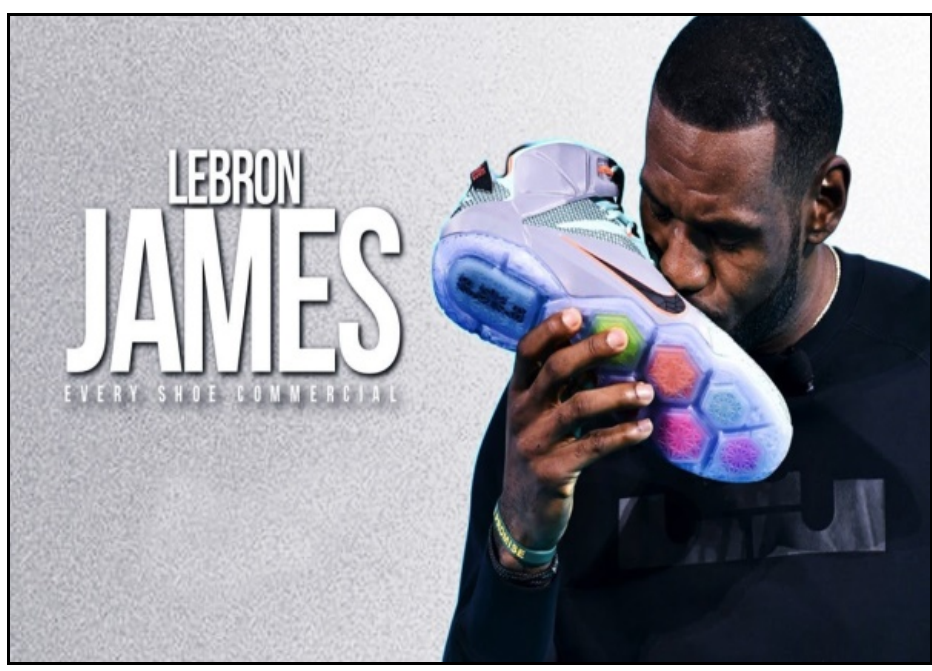

Figure 3. Experimental condition C-Celebrity-oriented symbolic cue 


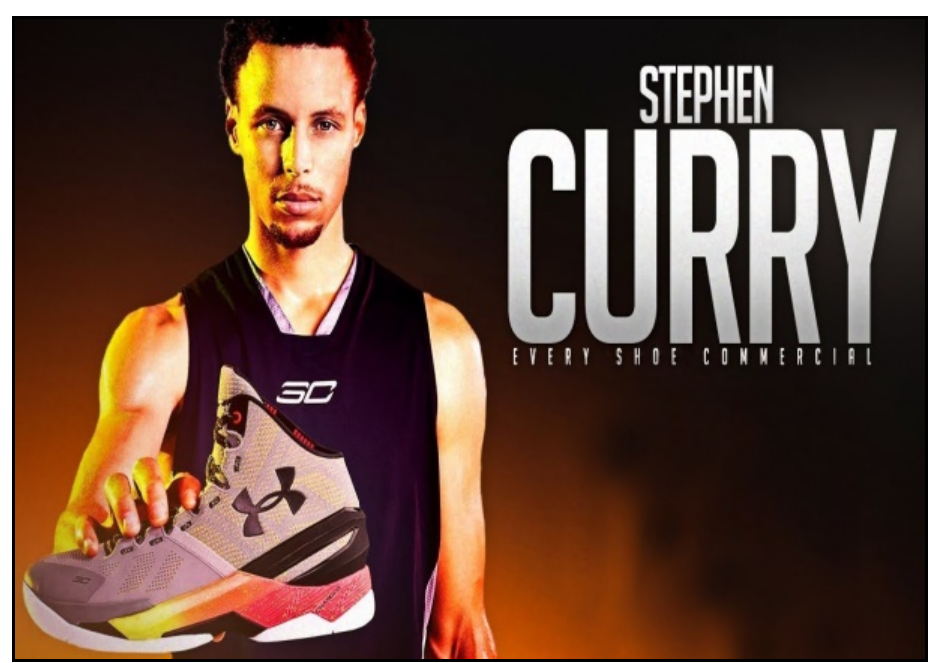

Figure 4. Experimental condition D—Celebrity-oriented symbolic cue

\subsection{Participants and Experiment}

This study used purposive sampling in two Taiwanese universities and recruited undergraduate and master's students studying electrical engineering, chemical engineering, engineering design, and visual design. The four proposed advertisements containing symbolic cues were labeled as experimental scenarios A-D. Each scenario was tested twice, with each group comprising 30-40 participants. Consequently, 282 valid responses (158 men and 124 female) were returned. The participants had an age range of $18-25$ years $(M=22.82)$, with 71 electrical engineering students $(25.2 \%), 64$ chemical engineering students $(22.7 \%), 78$ engineering design students (27.7\%), and 69 visual design students (24.4\%).

\subsection{Distribution of Product Involvement Samples}

Following previous studies, the present study employed post hoc segmentation (Meyers-Levy \& Malaviya, 1999; Yang, 2018); specifically, we summed the scores of items in the product involvement scale and used the median values of the scores as a reference to segment the samples (Haugtvedt \& Petty, 1992; Belanchea et al., 2017). The segmentation result is as follows: 144 participants with high-involvement $(51.1 \% ; M=24.78$ and score range $=19-35)$ and 138 participants with low-involvement $(49.9 \% ; M=11.69$ and score range $=5-17)$. The distribution of product involvement samples is illustrated in Table 1.

Table 1. Distribution of product involvement samples

\begin{tabular}{lllllll}
\hline & \multicolumn{2}{l}{ Experimental conditions } & & \\
\cline { 3 - 5 } & & \multicolumn{2}{l}{ Brand-oriented symbolic cues } & \multicolumn{2}{l}{ Celebrity-oriented symbolic cues } & \\
\cline { 3 - 5 } & & Condition A & Condition B & Condition C & Condition D & Total \\
\hline \multirow{2}{*}{ Product } & High-involvement & 37 & 35 & 39 & 33 & 144 \\
& Low-involvement & 31 & 40 & 30 & 37 & 138 \\
& Total & 68 & 75 & 69 & 70 & 282 \\
\hline
\end{tabular}

By performing a Cronbach's $\alpha$ test on the collected data using SPSS, we revealed internal consistency reliability values $(\alpha)$ of .91 in participants with high-involvement and .93 in participants with low-involvement, with both results achieving high levels of reliability $(\alpha>0.7)$. Subsequently, an independent $t$ test was conducted to evaluate the difference between the two sample groups; the results indicated that the differences were statistically significant $\left(t_{(280)}=21.43\right.$ and $\left.p=.000<.001\right)$. In other words, the two sample groups exhibited significant differences, indicating that product involvement was an appropriate independent variable for this study. Moreover, a Cronbach's $\alpha$ test revealed high internal consistency reliability in $\mathrm{A}_{\mathrm{ad}}(\alpha=.88)$ and $\mathrm{A}_{\mathrm{b}}(\alpha$ $=.91$ ).

\section{Data Analysis}

\subsection{Descriptive Statistics}

We first calculated the means of participant scores of each independent variable (Table 2) and obtained results as 
follows. The mean score $(M)$ of $\mathrm{A}_{\mathrm{ad}}$ in participants with high-involvement was $3.75(S D=1.21)$, and that in participants with low-involvement was $4.34(S D=1.13)$. Participants' mean scores of $\mathrm{A}_{\mathrm{b}}$ were $4.20(S D=1.09)$ in participants with high-involvement and $3.86(S D=1.02)$ in participants with low-involvement. Moreover, regarding $\mathrm{A}_{\mathrm{ad}}$ containing different symbolic cues, the mean attitude score in advertisements containing brand-oriented symbolic cues was $3.94(S D=1.24)$, and that in advertisements containing celebrity-oriented symbolic cues was $4.25(S D=1.04)$. Regarding $\mathrm{A}_{\mathrm{b}}$, the mean score in advertisements containing brand-oriented symbolic cues was $4.21(S D=1.02)$, and that in advertisements containing celebrity-oriented symbolic cues was $3.85(S D=1.16)$.

Table 2. Means and SDs of the dependent variables mediated by independent variables

\begin{tabular}{lllllll}
\hline & & \multicolumn{2}{c}{$\begin{array}{l}\text { Attitudes toward } \\
\text { advertisements }\left(\mathrm{A}_{\mathrm{ad}}\right)\end{array}$} & \multicolumn{2}{c}{$\begin{array}{l}\text { Attitudes toward } \\
\text { brands }\left(\mathrm{A}_{\mathrm{b}}\right)\end{array}$} \\
\cline { 3 - 7 } & & $n$ & $M$ & $S D$ & $M$ & $S D$ \\
\hline Product & High-involvement & 144 & 3.75 & 1.21 & 4.20 & 1.09 \\
involvement & Low-involvement & 138 & 4.34 & 1.13 & 3.86 & 1.02 \\
\hline Symbolic & Brand-oriented symbolic cues & 143 & 3.94 & 1.24 & 4.21 & 1.02 \\
consumption cues & Celebrity-oriented symbolic cues & 139 & 4.25 & 1.04 & 3.85 & 1.16 \\
\hline
\end{tabular}

\subsection{Influences of the Independent Variables on the Dependent Variable}

We performed an independent sample $t$ test to determine the influence of product involvement (independent variable 1$)$ and symbolic cues (independent variable 2$)$ on attitudes toward advertisements $\left(A_{a d}\right)$ and brands $\left(A_{b}\right)$. According to the test, the influence of product involvement on $\mathrm{A}_{\text {ad }}$ was significant $\left(M_{\text {low-involvement }}=4.34>\right.$ $M_{\text {high-involvement }}=3.75$, with $t_{(280)}=-2.95$ and $\left.p=.003<.01\right)$; the influence of symbolic cues on $\mathrm{A}_{\mathrm{ad}}$ was also significant $\left(M_{\text {celebrity-oriented symbolic cues }}=4.25>M_{\text {brand-oriented symbolic cues }}=3.94\right.$, with $t_{(280)}=-2.03$ and $\left.p=.046<.05\right)$. The influence of product involvement on $\mathrm{A}_{\mathrm{b}}$ was significant $\left(M_{\text {high-involvement }}=4.20>M_{\text {low-involvement }}=3.86\right.$, with $t_{(280)}=2.09$ and $\left.p=.041<.05\right)$; and the influence of symbolic cues on $\mathrm{A}_{\mathrm{b}}$ was significant $\left(M_{\text {brand-oriented symbolic cues }}\right.$ $=4.21>M_{\text {celebrity-oriented symbolic cues }}=3.85$, with $t_{(280)}=2.12$ and $\left.p=.039<.05\right)$.

Accordingly, product involvement and symbolic cues both exerted different effects on $A_{a d}$ and $A_{b}$. Subsequently, we conducted a two-way analysis of variance and discovered that the interaction ( $F$-values) between the effects of two independent variables $(\mathrm{A} \times \mathrm{B})$ on $\mathrm{A}_{\mathrm{ad}}(p=.000)$ and $\mathrm{A}_{\mathrm{b}}(p=.000)$ both exhibited statistical significance $(p<.001)$. Specifically, an interaction effect was observed between the effects of two independent variables on $\mathrm{A}_{\mathrm{ad}}$ and $\mathrm{A}_{\mathrm{b}}$ (Table 3).

Table 3. Analysis of variance on attitudes toward advertisements and brands

\begin{tabular}{llllll}
\hline Variances Source & $S S$ & $d f$ & $M S$ & $F$ & Sig. \\
\hline Attitudes toward advertisements $\left(\mathbf{A}_{\text {ad }}\right)$ & & & & & \\
Symbolic consumption cues (A) & 7.33 & 1 & 7.33 & 5.10 & $.045^{*}$ \\
Product involvement (B) & 17.52 & 1 & 17.52 & 4.48 & $.002^{* *}$ \\
A $\times$ B & 26.57 & 1 & 26.57 & 17.88 & $.000^{* * *}$ \\
\hline Attitudes toward brands (A $)$ & & & & & \\
Symbolic consumption cues (A) & 8.33 & 1 & 8.33 & 4.45 & $.036^{*}$ \\
Product involvement (B) & 7.94 & 1 & 7.94 & 4.23 & $.041^{*}$ \\
A $\times$ B & 41.46 & 1 & 4.46 & 22.13 & $.000^{* * *}$ \\
\hline
\end{tabular}

Note. ${ }^{*} \mathrm{p}<.05, \stackrel{ }{ }{ }^{* * *} \mathrm{p}<.01,{ }^{* * * *} \mathrm{p}<.001$.

This study tested the significance of the simple main effects of the independent variables and revealed that symbolic cues resulted in significantly different $\mathrm{A}_{\text {ad }}$ in participants with high-involvement $\left(F_{(1,137)}=18.79, p\right.$ $<.001)$; furthermore, such participants had a more positive attitude toward brand-oriented symbolic cues $(M=$ 4.31) than toward celebrity-oriented symbolic cues $(M=3.37)$. However, brand-oriented symbolic cues did not result in significantly different $\mathrm{A}_{\mathrm{ad}}$ in participants with low-involvement $(p=.216>.05)$.

Symbolic cues resulted in significantly different $A_{b}$ in participants with low-involvement $\left(F_{(1,143)}=18.79, p\right.$ $<.001)$; specifically, participants with low-involvement exhibited a more positive attitude toward celebrity-oriented symbolic cues $(M=4.42)$ than toward brand-oriented symbolic cues $(M=3.30)$. By contrast, 
symbolic cues did not lead to significantly different attitudes toward brands in participants with highinvolvement $(p=.07>.05)$. As shown in Table 4 , the two independent variables had opposite effects in $A_{a d}$ and $\mathrm{A}_{\mathrm{b}}$ (Table 4).

Table 4. Analysis of variance of test results of simple main effects

\begin{tabular}{|c|c|c|c|c|c|}
\hline Variances Source & SS & $d f$ & $F$ & Sig. & Post-hoc \\
\hline \multicolumn{6}{|l|}{ Attitudes toward advertisements $\left(\mathrm{A}_{\mathrm{ad}}\right)$} \\
\hline \multicolumn{6}{|l|}{ Symbolic consumption cues (A) } \\
\hline in $\mathrm{B} 1$ (Product high-involvement) & 30.25 & 1 & 18.79 & $.000^{* * *}$ & $\mathrm{~A} 1>\mathrm{A} 2$ \\
\hline in B2(Product low-involvement) & 3.06 & 1 & 1.55 & .216 & - \\
\hline \multicolumn{6}{|l|}{ Product involvement (B) } \\
\hline in A1 (Brand-oriented symbolic cue) & 1.48 & 1 & 1.26 & .610 & - \\
\hline in A2 (Celebrity-oriented symbolic cues) & 42.99 & 1 & 24.17 & $.000^{* * *}$ & $\mathrm{~B} 2>\mathrm{B} 1$ \\
\hline \multicolumn{6}{|l|}{ Attitudes toward brands $\left(A_{b}\right)$} \\
\hline \multicolumn{6}{|l|}{ Symbolic consumption cues (A) } \\
\hline in $\mathrm{B} 1$ (Product high-involvement) & 6.17 & 1 & 3.33 & .070 & - \\
\hline in $\mathrm{B} 2$ (Product low-involvement) & 44.44 & 1 & 23.48 & $.000^{* * *}$ & $\mathrm{~A} 2>\mathrm{A} 1$ \\
\hline \multicolumn{6}{|l|}{ Product involvement (B) } \\
\hline in A1 (Brand-oriented symbolic cue) & 43.48 & 1 & 22.67 & $.000^{* * *}$ & $\mathrm{~B} 1>\mathrm{B} 2$ \\
\hline in A2 (Celebrity-oriented symbolic cues) & 6.47 & 1 & 3.54 & .062 & - \\
\hline
\end{tabular}

Note. ${ }^{*} \mathrm{p}<.05,{ }^{* *} \mathrm{p}<.01,{ }^{* * *} \mathrm{p}<.001$.

\section{Discussion}

\subsection{Influence of Product Involvement Level on Consumer Attitudes}

The experimental results revealed that when participants were presented with advertisements containing symbolic cues, product involvement affected their attitudes toward advertisements and brands. Therefore, hypotheses $1 \mathrm{a}$ and $1 \mathrm{~b}$ were both supported. Furthermore, participants with low-involvement exhibited more positive attitudes toward advertisements than participants with high-involvement did, whereas participants with high-involvement exhibited more positive attitudes toward brands than participants with low-involvement did.

These experimental results were analyzed in-depth from the perspective of product involvement theory to explore the possible reasons behind them. Studies have shown that participants with high-involvement had more elaborative processing and evaluation regarding product information provided by advertisements and subsequently formed their attitudes toward the advertisements and brands (Petty, Cacioppo, \& Schumann, 1983). However, the advertisement containing symbolic cues used in the present study did not provide sufficient information for participants with high-involvement to elaborate further, thus leading to indistinct attitudes toward advertisements. Regarding attitudes toward brands, our sample advertisements effectively presented brand names and appearances of the advertised products, which enabled participants with high-involvement to follow the central route (Petty \& Cacioppo, 1984) when elaborating on brand information. Once the elaborated-upon brand information met the expectations of participants with high-involvement, their attitudes toward brands became more positive than those in participants with low-involvement. This study incorporated product involvement as an independent variable and investigated its influence on participant attitudes toward advertisements and brands; our experiment yielded results that were inconsistent with the conclusions in related studies. These differences occurred possibly because advertisements containing symbolic cues are usually accompanied by fewer advertisement-message arguments (Hennessey \& Anderson, 1990).

\subsection{Influence of Types of Symbolic Cues on Consumer Attitudes}

Our experimental results indicated that when participants were provided with advertisements containing symbolic cues, the types of symbolic cues affected consumer attitudes toward advertisements and brands. Thus, hypotheses $2 \mathrm{a}$ and $2 \mathrm{~b}$ were confirmed. Moreover, celebrity-oriented symbolic cues elicited more positive attitudes toward advertisements than brand-oriented symbolic cues did, whereas brand-oriented symbolic cues created more positive attitudes toward brands than celebrity-oriented symbolic cues did.

This study further analyzed the experimental results from the perspective of consumer culture theory. White and Hellerich (1998) argued that in contemporary society, people demonstrate their cultural identity through consumption. Symbolic consumption consolidates a person's self-esteem and connects people's lives to the society they belong to (Wattanasuwan, 2005). However, a symbolic meaning must be attached to an object 
before it can be purchased (Baudrillard, 1981). With the help of contemporary technology and media, brand identities and celebrity endorsements both provide symbols to products in symbolic consumption, and such symbols were underpinned by the creation of self-concept (Sirgy, 2015). In consumer culture, buying products from certain brands maintains the uniqueness of individual consumers and conveys their prestige and social status (O'Cass \& McEwen, 2004), and consumers are prone to buy products endorsed by celebrities to demonstrate their knowledge of particular products (Silvera \& Austad, 2003). These two phenomena of consumption are both considered conspicuous consumption behaviors. Our experimental results indicate that advertisements containing celebrity cues increased consumer attitudes toward advertisements and those containing brand-oriented symbolic cues increased their attitudes toward brands. The two symbolic cues created opposite outcomes, which provided insights for advertising agents that can assist them in establishing more specific advertising strategies through the concept of symbolic consumption.

\subsection{Influence of the Interaction Between Product Involvement and Symbolic Cues on Consumer Attitudes}

This study adopted two independent variables, namely product involvement and symbolic cues, between which an interaction effect was observed regarding their influences on attitudes toward advertisements and brands. A further analysis revealed that participants with high-involvement exhibited more positive attitudes toward advertisements containing brand-oriented symbolic cues than they did to those containing celebrity-oriented symbolic cues, whereas participants with low-involvement did not exhibit significant differences in their attitudes toward advertisements containing the two types of symbolic cues. Regarding attitudes toward brands, participants with low-involvement demonstrated more positive attitudes toward advertisements containing celebrity-oriented symbolic cues than they did toward those containing brand-oriented symbolic cues, whereas participants with high-involvement did not have a significantly different attitude toward the two types of cues. Accordingly, hypotheses $3 \mathrm{a}$ and $4 \mathrm{~b}$ were supported but hypotheses $3 \mathrm{~b}$ and $4 \mathrm{a}$ were rejected.

This study inferred possible reasons for the experimental results of participants with high-involvement as follows. Participants with high-involvement are considerably sensitive to product information provided in advertising text; they tend to be more active in seeking relevant information of products, learning about different brands and product types, and using their experience and knowledge of products to determine their attitudes toward information and make purchase decisions (Petty \& Cacioppo, 1981; Zaichkowsky, 1986). Accordingly, consumers with high-involvement take an elaborate approach to evaluating and managing product information provided in advertisements. Thus, advertisements that predominantly contain brand-oriented symbolic cues conform to such consumer needs because such advertisements provide clear information of brand names and product appearances, thereby creating more positive advertisement-related attitudes in consumers with high-involvement than those with low-involvement. However, this type of attitude is temporary, and thus whether such attitudes can be projected onto consumers' attitudes toward brands and affect subsequent purchase intentions requires further verification.

Theories related to product involvement suggest that consumers with low-involvement make purchase decisions and information judgments on a product according to their general impression of it, indicating that such consumers do not conduct in-depth processing of advertisement information (Petty \& Cacioppo, 1981; Zaichkowsky, 1986). Instead, these consumers might base their information processing and judgment on the fame of, their fondness for, and curiosity about celebrity endorsers, following the peripheral route of information processing (Petty \& Cacioppo, 1984). Therefore, advertisements that emphasize brand-oriented symbolic cues do not comply with the information processing and elaboration patterns of consumers with low-involvement, and advertisements containing celebrity-oriented symbolic cues can arguably elicit more positive attitudes toward brands in such consumers. However, determining whether the peripheral route of information processing strengthens subsequent purchase intentions requires a more in-depth verification.

\section{Conclusion}

The prevalence of novel technologies and engineering techniques has progressively reduced the differences between products. Therefore, consumers are engaged in more considerations when making purchase decisions between products of the same type; specifically, they consider product types, designs, prices, and most importantly, the symbolic value behind products. Symbolic consumption is pervasive in daily life. More cultural meanings and symbolic values have been incorporated in contemporary advertisements, and consumer needs have shifted from simply functional features of a product to their external, symbolic meanings. Thus, the hidden consumption-related meanings of products in advertisements arouse a stronger desire for product purchasing. How a symbolic meaning can be attached to a product has become particularly crucial in contemporary advertising markets, and enterprises must not ignore the influences of symbolic consumption. 
From the perspective of symbolic consumption theory, contemporary consumers do not only focus on functional features of a product when receiving advertising messages; instead, they incorporate their social identity and self-esteem into their consumption purposes. These consumers purchase products that contain social symbols they identify with, thus increasing their self-esteem and connecting their lives with the society they belong to; this phenomenon may be deemed a manifestation of symbolic consumption. In the era of symbolic consumption, the symbols behind products have become the fundamental reason for consumption; most people have shifted their focus from exclusively material to symbolic aspects of products. This transformation in consumer culture, a social phenomenon, has persuaded enterprises to employ more diverse advertising formats to shape the symbolic and consumption-related meanings behind products.

In addition to use and exchange values, products contain symbolic values created by marketing communications. The formation of a contemporary society starts from consumer culture; inarguably, people create self-concept and attain their sociocultural identity through consumption. Baudrillard (1981) stated that a symbolic meaning must be attached to objects before they can be purchased. The contemporary phenomenon of symbolic consumption, within the influential spheres of media and technology, has greatly affected people's attitudes toward consumption and their purchasing behaviors. Therefore, in a society where product symbolic meanings have become the foundation of consumption, enterprises must adopt more diverse advertising formats to shape the symbolic and consumption meanings behind products; otherwise, their products become indistinguishable from the vast array of other options.

\section{Acknowledgements}

The author gratefully acknowledges the support for this research provided by the Ministry of Science and Technology of Taiwan under Grants No. MOST-107-2410-H-131-001.

\section{References}

Aaker, D. A., \& Equity, M. B. (1991). Capitalizing on the value of a brand name. NY: Free Press.

Ahuvia, A. C. (2005). Beyond the extended self: Loved objects and consumers' identity narratives. Journal of Consumer Research, 32(1), 171-184. https://doi.org/10.1086/429607

Amos, C., Holmes, G., \& Strutton, D. (2008). Exploring the relationship between celebrity endorser effects and advertising effectiveness: A quantitative synthesis of effect size. International Journal of Advertising, 27(2), 209-234. https://doi.org/10.1080/02650487.2008.11073052

Arias-Bolzmann, L., Chakraborty, G., \& Mowen, J. C. (2000). Effects of absurdity in advertising: The moderating role of product category attitude and the mediating role of cognitive responses. Journal of Advertising, 29(1), 35-49. https://doi.org/10.1080/00913367.2000.10673602

Arnould, E. J., \& Thompson, C. (2007). Consumer culture theory (and we really mean theoretics): Dilemmas and opportunities posed by an academic branding strategy. Research in Consumer Behavior, 11, 3-12.

Atkin, C., \& Block, M. (1983). Effectiveness of celebrity endorsers. Journal of Advertising Research, 23(1), $57-61$.

Baudrillard, J. (2005). The system of objects. London: Verso.

Baudrillard, J. (2016). The consumer society: Myths and structures. London: Sage.

Bhat, S., \& Reddy, S. K. (1998). Symbolic and functional positioning of brands. Journal of Consumer Marketing, 15(1), 32-43. https://doi.org/10.1108/07363769810202664

Biswas, D., Biswas, A., \& Das, N. (2006). The differential effects of celebrity and expert endorsements on consumer risk perceptions. The role of consumer knowledge, perceived congruency, and product technology orientation. Journal of Advertising, 35(2), 17-31. https://doi.org/10.1080/00913367.2006.10639231

Biswas, S., Hussain, M., \& O’Donnell, K. (2009). Celebrity endorsements in advertisements and consumer perceptions: A cross-cultural study. Journal of Global Marketing, 22(2), 121-137. https://doi.org/10.1080/08911760902765940

Black, J., \& Bryant, J. (1995). Introduction to media communication: understand the past, experience the present, marvel at the future. NY: Brown \& Benchmark.

Caroll, A. (2009). Brand communications in fashion categories using celebrity endorsement. Brand Management, 17(2), 146-158. https://doi.org/10.1057/bm.2008.42 
Charles, K. K., Hurst, E., \& Roussanov, N. (2009). Conspicuous consumption and race. The Quarterly Journal of Economics, 124(2), 425-467. https://doi.org/10.1162/qjec.2009.124.2.425

DeRosia, E. D. (2008). The effectiveness of nonverbal symbolic signs and metaphors in advertisements: An experimental inquiry. Psychology \& Marketing, 25(3), 298-316. https://doi.org/10.1002/mar.20210

Dittmar, H., Beattie, J., \& Friese, S. (1996). Objects, decision considerations and self-image in men's and women's impulse purchases. Acta Psychologica, 93(1-3), 187-206. https://doi.org/10.1016/0001-6918(96)00019-4

Dodds, W. B., Monroe, K. B., \& Grewal, D. (1991). Effects of price, brand, and store information on buyers' product evaluations. Journal of Marketing Research, 28(3), 307-319. https://doi.org/10.2307/3172866

Eisend, M., \& Langner, T. (2010). Immediate and delayed advertising effects of celebrity endorsers' attractiveness and expertise. International Journal of Advertising, 29(4), 527-546. https://doi.org/10.2501/S0265048710201336

Ekinci, Y., Sirakaya-Turk, E., \& Preciado, S. (2013). Symbolic consumption of tourism destination brands. Journal of Business Research, 66(6), 711-718. https://doi.org/10.1016/j.jbusres.2011.09.008

Elliott, R. (1997). Existential consumption and irrational desire. European Journal of Marketing, 31(3-4), 285-296. https://doi.org/10.1108/03090569710162371

Elliott, R., \& Wattanasuwan, K. (1998). Consumption and the symbolic project of the self. European Advances in Consumer Research, 3, 17-20. https://doi.org/10.1080/02650487.1998.11104712

Erdogan, B. Z., Baker, M. J., \& Tagg, S. (2001). Selecting celebrity endorsers: The practitioner's perspective. Journal of Advertising Research, 41(3), 39-48. https://doi.org/10.2501/JAR-41-3-39-48

Faircloth, J. B., Capella, L. M., \& Alford, B. L. (2001). The effect of brand attitude and brand image on brand equity. Journal of Marketing Theory and Practice, 9(3), 61-75. https://doi.org/10.1080/10696679.2001.11501897

Firat, A. F., Sherry, J. F., \& Venkatesh, A. (1994). Postmodernism, marketing and the consumer. International Journal of Research in Marketing, 11(4), 311-316. https://doi.org/10.1016/0167-8116(94)90009-4

Fournier, S. (1998). Consumers and their brands: Developing relationship theory in consumer research. Journal of Consumer Research, 24(4), 343-373. https://doi.org/10.1086/209515

Gabriel, Y., \& Lang, T. (1995). The unmanageble consumer: Contemporary consumption and its fragmentations. London: SAGE Publications.

Ger, G., \& Belk, R. W. (1996). Cross-cultural differences in materialism. Journal of Economic Psychology, 17(1), 55-77. https://doi.org/10.1016/0167-4870(95)00035-6

Giddens, A. (2013). Modernity and self-identity: Self and society in the late modern age. NY: John Wiley \& Sons.

Goldsmith, R. E., Lafferty, B. A., \& Newell, S. J. (2000). The impact of corporate credibility and celebrity credibility on consumer reaction to advertisements and brands. Journal of Advertising, 29(3), 43-54. https://doi.org/10.1080/00913367.2000.10673616

Greenwald, A. G., \& Leavitt, C. (1984). Audience involvement in advertising: Four levels. Journal of Consumer Research, 11(1), 581-592. https://doi.org/10.1086/208994

Hawton, K., \& Williams, K. (2005). Media influences on suicidal behaviour: Evidence and prevention. In K. Hawton (Ed.), Prevention and treatment of suicidal behaviour: From science to practice (pp. 293-306). Oxford: Oxford University Press. https://doi.org/10.1093/med/9780198529767.003.0017

Herbig, P., \& Milewicz, J. (1995). The relationship of reputation and credibility to brand success. Journal of Consumer Marketing, 12(4), 5-10. https://doi.org/10.1108/EUM0000000002601

Hetsroni, A. (2000). The relationship between values and appeals in Israeli advertising: A smallest space analysis. Journal of Advertising, 29(3), 55-68. https://doi.org/10.1080/00913367.2000.10673617

Holt, D. B. (1995). How consumers consume: A typology of consumption practices. Journal of Consumer Research, 22(1), 1-16. https://doi.org/10.1086/209431

Holt, D. B. (2004). How brands become icons: The principles of cultural branding. Harvard Business Press.

Homer, P. M. (1990). The mediating role of attitude toward the ad: Some additional evidence. Journal of 
Marketing Research, 27(1), 78-86. https://doi.org/10.1177/002224379002700108

Houston, M. J. (1977). A paradigm for research on consumer involvement. Graduate School of Business, University of Wisconsin-Madison.

Hsu, C. K., \& McDonald, D. (2002). An examination on multiple celebrity endorsers in advertising. Journal of Product \& Brand Management, 11(1), 19-29. https://doi.org/10.1108/10610420210419522

Jansen, B. J., Sobel, K., \& Zhang, M. (2011). The brand effect of key phrases and advertisements in sponsored search. International Journal of Electronic Commerce, 16(1), 77-106. https://doi.org/10.2753/JEC1086-4415160103

Kahle, L. R., \& Homer, P. M. (1985). Physical attractiveness of the celebrity endorser: A social adaptation perspective. Journal of Consumer Research, 11(4), 954-961. https://doi.org/10.1086/209029

Kamins, M. A. (1989). Celebrity and non-celebrity advertising in a two-sided context. Journal of Advertising Research, 29(3), 34-42.

Kassarjian, H. H. (1981). Low-involvement: A second look. Advances in Consumer Research, 8(1), 31-34.

Kay, M. J. (2006). Strong brands and corporate brands. European Journal of Marketing, 40(7-8), 742-760. https://doi.org/10.1108/03090560610669973

Khairullah, D. Z., \& Khairullah, Z. Y. (2013). Cultural values in Indian television advertising. Journal of Promotion Management, 19(2), 265-281. https://doi.org/10.1080/10496491.2013.769477

Kim, S. S., Lee, J., \& Prideaux, B. (2014). Effect of celebrity endorsement on tourists' perception of corporate image, corporate credibility and corporate loyalty. International Journal of Hospitality Management, 37, 131-145. https://doi.org/10.1016/j.ijhm.2013.11.003

Krugman, H. E. (1965). The impact of television advertising: Learning without involvement. Public Opinion Quarterly, 29(3), 349-356. https://doi.org/10.1086/267335

Lastovicka, J. L., \& Gardner, D. M. (1978). Low-involvement versus high-involvement cognitive structures. Advances in Consumer Research, 5(1), 87-92.

Lee, D. H. (1990). Symbolic interactionism: some implications for consumer self-concept and product symbolism research. Advances in Consumer Research, 17(1), 386-393.

Lee, E. J. (2013). A prototype of multicomponent brand personality structure: A consumption synmbolism approach. Psychology \& Marketing, 30(2), 173-186. https://doi.org/10.1002/mar.20596

Lee, J. G., \& Thorson, E. (2008). The impact of celebrity-product incongruence on the effectiveness of product endorsement. Journal of Advertising Research, 48(3), 433-449. https://doi.org/10.2501/S0021849908080446

Luna-Cortés, G. (2017). The influence of symbolic consumption on experience value and the use of virtual social networks. Spanish Journal of Marketing, 21(1), 39-51. https://doi.org/10.1016/j.sjme.2016.12.005

Machiels, C. J., \& Karnal, N. (2016). See how tasty it is? Effects of symbolic cues on product evaluation and taste. Food Quality and Preference, 52, 195-202. https://doi.org/10.1016/j.foodqual.2016.04.014

MacKenzie, S. B., Lutz, R. J., \& Belch, G. E. (1986). The role of attitude toward the ad as a mediator of advertising effectiveness: A test of competing explanations. Journal of Marketing Research, 23(2), 130-143. https://doi.org/10.1177/002224378602300205

McCracken, G. (1989). Who is the celebrity endorser? Cultural foundations of the endorsement process. Journal of Consumer Research, 16(3), 310-321. https://doi.org/10.1086/209217

O'cass, A., \& McEwen, H. (2004). Exploring consumer status and conspicuous consumption. Journal of Consumer Behaviour, 4(1), 25-39. https://doi.org/10.1002/cb.155

Park, S. Y., \& Yang, Y. (2010). The effect of celebrity conformity on the purchase intention of celebrity sponsorship brand: The moderating effects of symbolic consumption and face-saving. Journal of Global Fashion Marketing, 1(4), 215-229. https://doi.org/10.1080/20932685.2010.10593073

Petruzzellis, L. (2010). Mobile phone choice: technology versus marketing. The brand effect in the Italian market. European Journal of Marketing, 44(5), 610-634. https://doi.org/10.1108/03090561011032298

Petty, R. E., Cacioppo, J. T., \& Schumann, D. (1983). Central and peripheral routes to advertising effectiveness: The moderating role of involvement. Journal of Consumer Research, 10(2), 135-146. 
https://doi.org/10.1086/208954

Priem, R. L. (2007). A consumer perspective on value creation. Academy of Management Review, 32(1), 219-235. https://doi.org/10.5465/amr.2007.23464055

Priester, J. R., \& Petty, R. E. (2003). The influence of spokesperson trustworthiness on message elaboration, attitude strength, and advertising effectiveness. Journal of Consumer Psychology, 13(4), 408-421. https://doi.org/10.1207/S15327663JCP1304_08

Quester, P. G., Karunaratna, A., \& Lim, A. L. (2003). Product involvement/brand loyalty: is there a link? Journal of Product \& Brand Management, 12(1), 22-38. https://doi.org/10.1108/10610420310463117

Reed, A. (2002). Social identity as a useful perspective for self - concept-based consumer research. Psychology \& Marketing, 19(3), 235-266. https://doi.org/10.1002/mar.10011

Richins, M. L. (1994). Special possessions and the expression of material values. Journal of Consumer Research, 21(3), 522-533. https://doi.org/10.1086/209415

Schembri, S., Merrilees, B., \& Kristiansen, S. (2010). Brand consumption and narrative of the self. Psychology \& Marketing, 27(6), 623-637. https://doi.org/10.1002/mar.20348

Schultz, C. D. (2008). Consumer trust in E commerce: An analysis of means communicating trustworthiness from a buying transaction life cycle perspective. Hamburg: Verlag.

Servidio, R. (2015). Images, affective evaluation and personality traits in tourist behaviour: An exploratory study with Italian postcards. Tourism Management Perspectives, 16, 237-246. https://doi.org/10.1016/j.tmp.2015.08.003

Shimp, T. A. (1993). Promotion management \& marketing communications. NY: Dryden Press.

Sirgy, M. J. (1982). Self-concept in consumer behavior: A critical review. Journal of Consumer Research, 9(3), 287-300. https://doi.org/10.1086/208924

Slater, D. (1997). Consumer culture and modernity. London: Wiley.

Sridevi, J. (2014). Effectiveness of celebrity advertisement on select FMCG-an empirical study. Procedia Economics and Finance, 11, 276-288. https://doi.org/10.1016/S2212-5671(14)00196-8

Stratton, G., \& Northcote, J. (2016). When totems beget clans: The brand symbol as the defining marker of brand communities. Journal of Consumer Culture, 16(2), 493-509. https://doi.org/10.1177/1469540514528194

Supanvanij, J., \& Amine, L. S. (2000). Consumer perception of country-of-origin effect and brand effect. Latin American Business Review, 1(4), 47-60. https://doi.org/10.1300/J140v01n04_03

Szymanowski, M., \& Gijsbrechts, E. (2012). Consumption-based cross-brand learning: Are private labels really private? Journal of Marketing Research, 49(2), 231-246. https://doi.org/10.1509/jmr.07.0416

Traylor, M. B. (1981). Product involvement and brand commitment. Journal of Advertising Research, 21(6), $51-56$.

Vakratsas, D., \& Ambler, T. (1999). How advertising works: what do we really know? The Journal of Marketing, 63(1), 26-43. https://doi.org/10.1177/002224299906300103

Wattanasuwan, K. (2005). The self and symbolic consumption. Journal of American Academy of Business, 6(1), $179-184$.

White, D. R., \& Hellerich, G. (1998), Labyrinths of the mind: The self in the postmodern age. Albany: State University of New York Press.

Yang, C. M. (2018). Effects of Message Strategy and Need for Cognition (NFC) on Consumer Attitudes: A Case of Corporate Social Responsibility (CSR) Advertising. Open Journal of Business and Management, 6(3), 714-732. https://doi.org/10.4236/ojbm.2018.63055

Yip, P. S. et al. (2006). The effects of a celebrity suicide on suicide rates in Hong Kong. Journal of Affective Disorders, 93(1), 245-252. https://doi.org/10.1016/j.jad.2006.03.015

Zahl, D. L., \& Hawton, K. (2004). Media influences on suicidal behaviour: An interview study of young people. Behavioural and Cognitive Psychotherapy, 32(2), 189-198. https://doi.org/10.1017/S1352465804001195

Zaichkowsky, J. L. (1986). Conceptualizing involvement. Journal of Advertising, 15(2), 4-34. https://doi.org/10.1080/00913367.1986.10672999 


\section{Copyrights}

Copyright for this article is retained by the author, with first publication rights granted to the journal.

This is an open-access article distributed under the terms and conditions of the Creative Commons Attribution license (http://creativecommons.org/licenses/by/4.0/). 